\title{
Light-Emitting Diode-Assisted Narrow Band Imaging Video Endoscopy System in Head and Neck Cancer
}

\author{
Hsin-Jen Chang ${ }^{1}$, Wen-Hung Wang ${ }^{1}$, Yen-Liang Chang ${ }^{1}$, Tzuan-Ren Jeng ${ }^{2}$, Chun-Te $\mathrm{Wu}^{2}$, Ludovic Angot ${ }^{2}$, \\ Chun-Hsing Lee ${ }^{2}$ and Pa-Chun Wang ${ }^{1}$ \\ ${ }^{1}$ Department of Otolaryngology, Head and Neck Surgery, Cathay General Hospital, Taipei, ${ }^{2}$ Electronic and Optoelectronic Research Laboratories, \\ Industrial Technology Research Institute, Hsinchu, Taiwan
}

Background/Aims: To validate the effectiveness of a newly developed light-emitting diode (LED)-narrow band imaging (NBI) system for detecting early malignant tumors in the oral cavity.

Methods: Six men (mean age, 51.5 years) with early oral mucosa lesions were screened using both the conventional white light and LEDNBI systems.

Results: Small elevated or ulcerative lesions were found under the white light view, and typical scattered brown spots were identified after shifting to the LED-NBI view for all six patients. Histopathological examination confirmed squamous cell carcinoma. The clinical stage was early malignant lesions (T1), and the patients underwent wide excision for primary cancer. This is the pilot study documenting the utility of a new LED-NBI system as an adjunctive technique to detect early oral cancer using the diagnostic criterion of the presence of typical scattered brown spots in six high-risk patients.

Conclusions: Although large-scale screening programs should be established to further verify the accuracy of this technology, its lower power consumption, lower heat emission, and higher luminous efficiency appear promising for future clinical applications.

Key Words: Light-emitting diode; Narrow band imaging; Endoscopy; Screening; Mouth neoplasms

\section{INTRODUCTION}

Most cases of head and neck cancer are encountered in the late stages, and as such, these lesions can be easily detected by standard endoscopy. By contrast, superficial mucosal cancer in the early stages often has occult or shallow layer lesions that may be overlooked by standard endoscopy.

The detection of recurrent or second primary tumors in the early stages of disease results in better outcomes after salvage chemotherapy. However, because of the limited availability of clinical diagnostic tools, two-thirds of patients requiring salvage chemotherapy have their diseases diagnosed only after the tumors have progressed to locally advanced cancers. ${ }^{2}$

Received: April 11, 2014 Accepted: June 12, 2014

Correspondence: $\mathrm{Pa}-\mathrm{Chun}$ Wang

Department of Otolaryngology, Cathay General Hospital, 280 Sec 4, Jen-Ai Rd, 106 Taipei, Taiwan

Tel: +886-2-2708-2121, Fax: +886-2-6636-2836, E-mail: drtony@seed.net.tw

(c) This is an Open Access article distributed under the terms of the Creative Commons Attribution Non-Commercial License (http://creativecommons.org/ licenses/by-nc/3.0) which permits unrestricted non-commercial use, distribution, and reproduction in any medium, provided the original work is properly cited.
The use of narrow band imaging (NBI) is currently considered of great benefit in detecting superficial mucosal lesions over the pharyngeal mucosa. ${ }^{3}$ A literature review revealed that the effectiveness of NBI in the early detection of head and neck squamous cell carcinoma (SCC) of the larynx, ${ }^{4}$ mouth floor, ${ }^{5}$ nasopharynx, ${ }^{6}$ oropharynx, and hypopharynx ${ }^{7,8}$ has been documented over time. The NBI system (Olympus Medical Systems, Tokyo, Japan) is a noninvasive optical device that uses reflected light to visualize the superficial structure and enhance vasculature within the mucosal layer. NBI provides a unique image that emphasizes the morphological and structural character of lesions as well as their surface capillary patterns. The first clinical study of the NBI system for the diagnosis of gastrointestinal tumors was reported by Sano et al. ${ }^{9}$ in 2001 . Unique images are created by the sequential lighting of the tissue through an endoscope, and the sequence of light is produced by a rotation disk with red, green, and blue optical filters placed in front of a high-power white light source, typically a xenon lamp. The physical phenomena are based on the fact that the penetration depth of light is dependent on its wavelength (i.e., 
the longer the wavelength, the deeper the penetration), and visible blue light only penetrates superficial areas of the tissue. Therefore, the use of white light combined with a special narrow-band filter ( 400 to $430 \mathrm{~nm}$ for blue, 430 to $460 \mathrm{~nm}$ for green, 485 to $515 \mathrm{~nm}$ for red) enables imaging of the superficial tissue structures with an increased contrast compared with pure white light. ${ }^{10}$

A literature review found that all of the studies about the effectiveness of NBI in the early detection of head-and-neck SCC used "brownish spots" as the typical image pattern for detecting early cancerous lesions. ${ }^{4,7,8,11}$ As such, brownish spots appear to have become a gold standard in identifying early mucosal head and neck cancer.

However, current commercially available NBI systems based on xenon lamps remain expensive and have higher power consumption, thus restricting their widespread use in general clinical practice. As we know, the light source for light-emitting diodes (LEDs) has lower power consumption, emits much less heat, and exhibits higher luminous efficiency. ${ }^{12}$ Therefore, the objectives of this pilot study were to develop and validate the usefulness of a new NBI system based on an LED light source for detecting early malignant tumors in the oral cavity for highrisk patients.

\section{MATERIALS AND METHODS}

\section{Study participants}

The present study was a pilot study conducted at a tertiary referral center. From January 1, 2012 through July 1, 2012, a total of six men (mean \pm SD age, $51.5 \pm 13$ years) (Table 1 ) with early oral cavity cancer (T1) were enrolled. These patients underwent video endoscopic screening using both conventional white light and LED-NBI systems. Two patients (cases 1 and 4) previously completed treatment for oral cancer, and the remaining patients had heavy betel nut chewing habits. The screening was undertaken during their routine outpatient department sessions without any clinical complaint.

The criteria for diagnosing a cancerous lesion with conventional white light endoscopic imaging included the presence of elevated lesions and ulcerative lesions. The criterion for classifying a lesion as malignant using the NBI system was the presence of a well-demarcated brownish area with scattered brown spots (Fig. 1), as we described in our previously published paper. ${ }^{10}$ Patients with lesions that were deemed noncancerous by these diagnostic methods did not undergo any additional examinations or biopsy. On the contrary, patients determined to have abnormal lesions underwent biopsy or lesion resection.

The study was approved by the Ethics Committee of Cathay General Hospital, and written informed consent was obtained from all patients before the endoscopic examinations and tumor excision.

\section{NBI equipment and procedure}

\section{Industrial Technology Research Institute of Taiwan NBI system}

The present study uses an LED-equipped NBI light source. The system is shown in Fig. 2A. The Industrial Technology Research Institute of Taiwan (ITRI) NBI system is based on three LED light sources: green, blue, and white. The white LED source allows working in bright light mode, as a traditional light fountain is typically used for endoscopes. The other mode mixes green and blue light with the purpose of obtaining the same effect as that produced with the Olympus NBI system, as

Table 1. Clinical Characteristics of Six High-Risk Patients with Early Oral Cancer Detected by Endoscopy

\begin{tabular}{|c|c|c|c|c|c|c|}
\hline No. & Age/Sex & Previous history & NBI examination & Site of biopsy & Diagnosis & Treatment \\
\hline 1 & $72 / \mathrm{M}$ & $\begin{array}{l}\text { Lip SCC (T1N0M0 stage I) } \\
\text { Right buccal SCC (T1M0N0 stage I) } \\
\text { Left buccal hybrid (verrucous-squamous) } \\
\text { carcinoma (T2N0M0 stage II) }\end{array}$ & $\begin{array}{l}\text { Scattered brown } \\
\text { spots }\end{array}$ & $\begin{array}{l}\text { Left buccal } \\
\text { mucosa }\end{array}$ & $\begin{array}{l}\text { SCC (T1N0M0 } \\
\text { stage I) }\end{array}$ & Excision \\
\hline 2 & $56 / \mathrm{M}$ & Nil & $\begin{array}{l}\text { Scattered brown } \\
\text { spots }\end{array}$ & $\begin{array}{l}\text { Left lateral } \\
\text { tongue }\end{array}$ & $\begin{array}{l}\text { Tongue SCC } \\
\text { (T1N0M0 stage I) }\end{array}$ & $\begin{array}{l}\text { Left partial } \\
\text { glossectomy+CCRT }\end{array}$ \\
\hline 3 & $51 / \mathrm{M}$ & Right buccal leukoplakia & $\begin{array}{l}\text { Scattered brown } \\
\text { spots }\end{array}$ & $\begin{array}{l}\text { Right buccal } \\
\text { mucosa }\end{array}$ & $\begin{array}{l}\text { Buccal SCC } \\
\text { (T1N0M0 stage 1) }\end{array}$ & Excision \\
\hline 4 & $38 / \mathrm{M}$ & $\begin{array}{l}\text { Left tongue SCC (T4aN0M0 stage IVA) } \\
\text { status hemiglossectomy, post-CCRT }\end{array}$ & $\begin{array}{l}\text { Scattered brown } \\
\text { spots }\end{array}$ & $\begin{array}{l}\text { Left retromolar } \\
\text { trigone }\end{array}$ & $\begin{array}{l}\text { SCC (rpT1N0M0 } \\
\text { stage I) }\end{array}$ & $\begin{array}{l}\text { Excision+ } \\
\text { chemotherapy }\end{array}$ \\
\hline 5 & $43 / \mathrm{M}$ & Diabetes mellitus & $\begin{array}{l}\text { Scattered brown } \\
\text { spots }\end{array}$ & Left tonsil & SCC (T1N0M0) & Excision+RT \\
\hline 6 & $61 / \mathrm{M}$ & $\begin{array}{l}\text { Hypertension } \\
\text { CAD }\end{array}$ & $\begin{array}{l}\text { Scattered brown } \\
\text { spots }\end{array}$ & $\begin{array}{l}\text { Left buccal } \\
\text { mucosa }\end{array}$ & $\begin{array}{l}\text { SCC (T1N1M0 } \\
\text { stage III) }\end{array}$ & $\begin{array}{l}\text { Excision+neck } \\
\text { Dissection+RT }\end{array}$ \\
\hline
\end{tabular}

NBI, narrow band imaging; M, male; SCC, squamous cell carcinoma; CCRT, concurrent chemoradiotherapy; RT, radiotherapy; CAD, cardiovascular disease. 

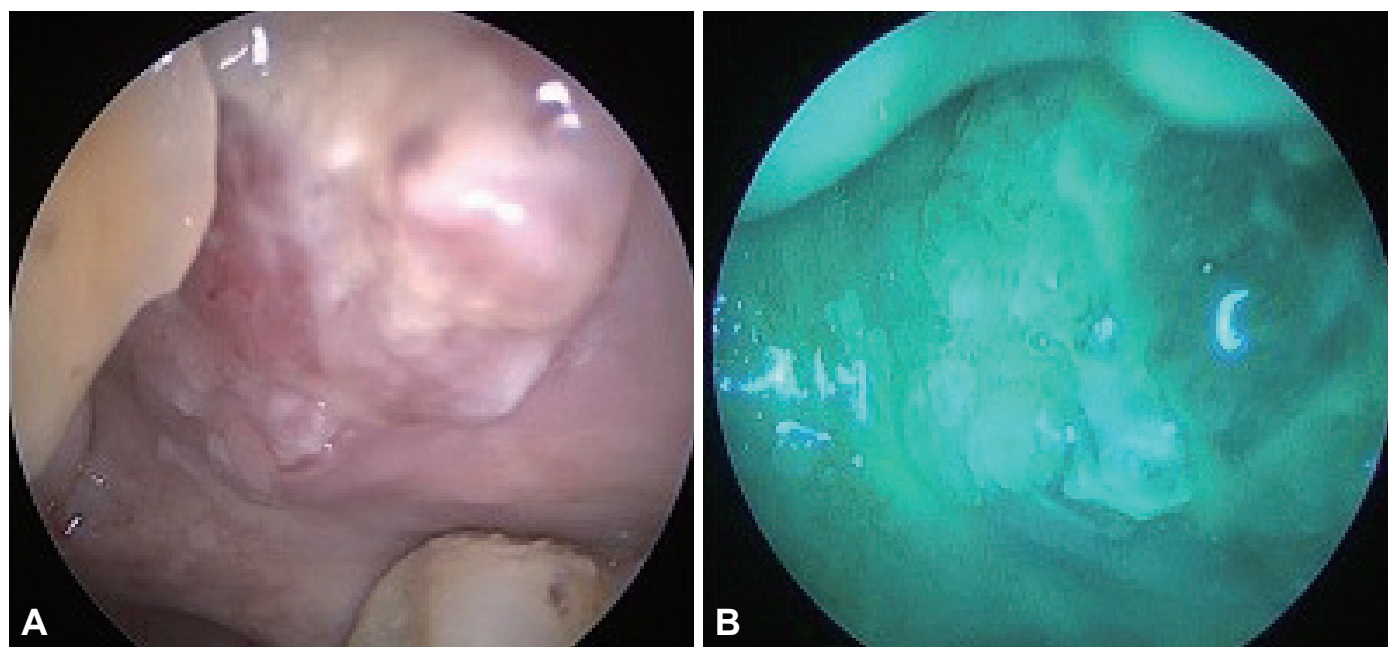

Fig. 1. Case 6, (A) left buccal mucosa lesion $\left(1.8 \times 1.7 \mathrm{~cm}^{2}\right)$. (B) The narrow band imaging examination uncovered a well-demarcated brownish area with scattered brown spots. Histopathology revealed squamous cell carcinoma, moderately differentiated.
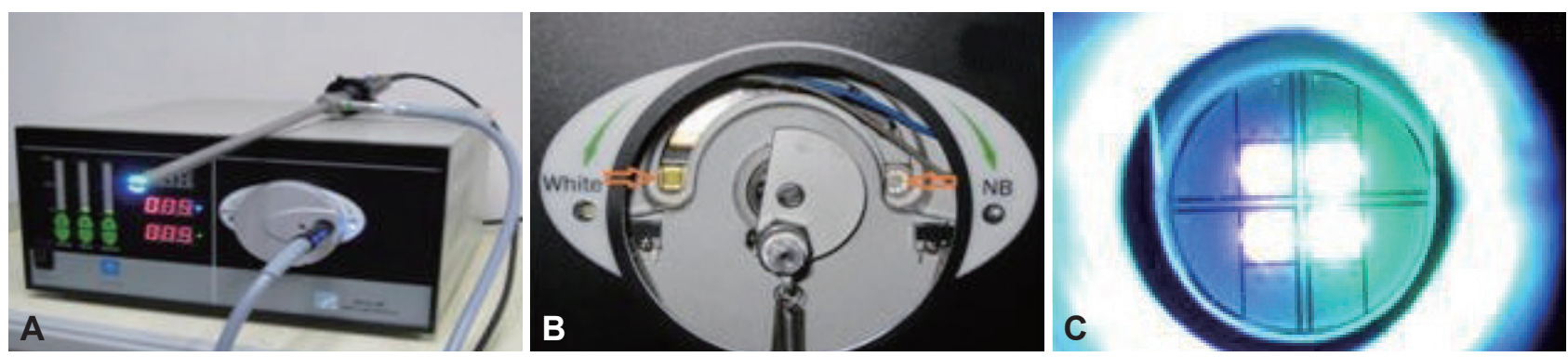

Fig. 2. (A) Light-emitting diode (LED)-narrow band imaging light source $P R 650$, cursors for $0 \%$ to $100 \%$ white, green/blue light mix. (B) Left $\Rightarrow$ : white LED chip; right $\diamond$ : green/blue LED chips. (C) Close-up view: green/blue LED chips.

shown in Fig. 2B. The central wavelength and bandwidth of the blue LED are 415 and $30 \mathrm{~nm}$, respectively, compared to 528 and $40 \mathrm{~nm}$, respectively, for the green LED. As shown in Fig. $2 \mathrm{C}$, there are four chips packaged on a single die that were designed specifically for the light source. The brightness of the blue and green LED units can be tuned independently. The power is supplied by a pulse width modulation unit. The white LED is rated at $12 \mathrm{~A}$, whereas the blue and green LEDs are both rated at $660 \mathrm{~mA}$.

The NBI system was equipped with a videoscope, light source, and head light. A button on the control section of the videoscope enabled switching between the conventional and NBI views. All endoscopic examinations were performed by one experienced otolaryngologist (HJC) in the outpatient clinic. The patients were examined while in the seated position. Before the endoscopic procedure, the oral cavity of each patient was anesthetized with a $4 \%$ lidocaine hydrochloride spray. The oral cavity and oropharynx were first examined by direct visual inspection and palpation and subsequently by transoral endoscopy, first in the white light mode and then using the NBI system.

\section{RESULTS}

Small elevated or ulcerative lesions were found under the white light view, and typical scattered brown spots were identified after shifting to the LED-NBI view for all six patients. The effectiveness of LED-NBI using "brownish spots" as the typical gold standard image pattern for detecting these early cancerous lesions appears encouraging. Histopathological examination also confirmed SCC (Fig. 1). The clinical stage was early malignant lesions (T1), and the patients underwent wide excision for primary cancer, with four patients also receiving postoperative radiotherapy or chemotherapy (Table 1).

\section{DISCUSSION}

Head and neck cancer screening could be an effective method for detecting positive findings of head and neck cancer in at-risk populations because early-stage head and neck cancer might be discovered while it is more readily treatable. To date, visual examination and palpation have remained the standard techniques for the identification of mucosal lesions of the head and neck. ${ }^{13,14} \mathrm{~A}$ comprehensive examination of the head, neck, 
and primary lesion site during routine examinations is crucial. The reported feasibility of conventional oral examinations for detecting oral cancer has varied among previous studies. Although conventional physical examination may be useful for identifying oral lesions, it is not as effective for identifying other potentially premalignant lesions. ${ }^{15}$

NBI-assisted endoscopy is highly useful for the detection of precancerous lesions in the oropharyngeal and hypopharyngeal mucosa, and it is not affected by a history of radiotherapy in patients with head and neck SCC. ${ }^{10}$ A commercial available NBI system was equipped with a videoscope, light source, and central video control system (Olympus Medical Systems). A button on the control section of the videoscope enabled switching between the conventional and NBI views.

We developed a new NBI system using an LED light source and found that it also could be practical for detecting early cancerous lesions using the diagnostic criterion of the presence of scattered brown spots in our pilot study. Table 2 shows the differences between the Olympus NBI and ITRI systems in terms of spectral properties. The ITRI LED system has a 2-fold larger bandwidth for the green LED and an offset of $12 \mathrm{~nm}$ for that color. The features of the blue color are closer to those of the Olympus NBI system, with only a shift of $5 \mathrm{~nm}$ for the center wavelength and a 1.5-fold larger bandwidth. The life span of the ITRI LED light source exceeds 20,000 hours.

Despite the spectral differences from the Olympus NBI, the advantages of the LED are however multiple. First, LEDs are

Table 2. Comparison of Spectral Properties between the Olympus and ITRI Systems

\begin{tabular}{lcc}
\hline & ITRI, nm & Olympus, $\mathrm{nm}$ \\
\hline Green center wavelength & 528 & 540 \\
Green bandwidth & 40 & 20 \\
Blue center wavelength & 415 & 420 \\
Blue bandwidth & 30 & 20 \\
\hline
\end{tabular}

ITRI, Industrial Technology Research Institute of Taiwan. solid-state chips and therefore can withstand mishandling much better than traditional xenon or halogen bulbs, which contain a filament. Additionally, because of the absence of a burning filament, LEDs outlast the life span of filament lamps by a factor of 10 to several hundred, with a life span of more than 20,000 hours for the ITRI LED. Another advantage is that for the same luminous flux, the power consumption of an LED is much lower than that of a filament lamp. A direct consequence of the previous advantage is that LED light sources emit much less heat than their filament-based counterparts. The luminous efficiency of LEDs is higher than that of filament lamps. Finally, LED chips can be tuned to a bandwidth and center wavelength according to specific requirements, rendering the use of a highpower light source and rotating filter obsolete (Table 3 ).

The goal of screening for high-risk populations requires both rapidity and convenience, but the goals of low cost and higher efficiency should also be considered seriously in the future. Our preliminary data revealed that the ITRI NBI system can achieve the same imaging performance for early cancer detection as the xenon NBI system, but the main advantages of the ITRI NBI system are lower power consumption, lower heat emission, and higher luminous efficiency. A large-scale screening program should be established to investigate the actual accuracy of the ITRI NBI system.

In conclusion, this is a pilot study documenting the utility of a new LED-NBI system as an adjunctive technique to detect early oral cancer using the diagnostic criterion of the presence of typical scattered brown spots in six high-risk patients. Although a large-scale screening program should be established to further verify the accuracy of this technique in daily practice, its lower power consumption, lower heat emission, and higher luminous efficiency appear promising for future clinical applications.

\section{Conflicts of Interest}

The authors have no financial conflicts of interest.

Table 3. Comparison of the Main Specifications between the Olympus NBI and ITRI Systems

\begin{tabular}{|c|c|c|}
\hline & ITRI & Olympus $^{\text {a) }}$ \\
\hline Dimensions, $\mathrm{W} \times \mathrm{H} \times \mathrm{D}, \mathrm{mm}$ & $320 \times 175 \times 335$ & $381 \times 162 \times 536$ \\
\hline Weight, kg & 3 & 16 \\
\hline \multirow[t]{2}{*}{ Power consumption, VA } & 45 (white) & 500 \\
\hline & 20 (narrow band) & \\
\hline Lamp & 1 White LED and 1 green/blue LED array & Xenon $300 \mathrm{~W}$ \\
\hline Main functions & $\begin{array}{l}\text { White light and specific spectral observation: } \\
\text { NBI in green and blue; } 99 \text { levels of light adjustment } \\
\text { (independently for white or green+blue) }\end{array}$ & $\begin{array}{l}\text { Specific spectral observation: NBI } \pm 8 \text {-level automatic } \\
\text { light level adjustment, } 3 \text { fan levels (low, medium, } \\
\text { high), automatic switching of emergency lights }\end{array}$ \\
\hline
\end{tabular}

NBI, narrow band imaging; ITRI, Industrial Technology Research Institute of Taiwan; VA, volt-Ampere; LED, light-emitting diode.

${ }^{a)}$ Specifications of the EVIS LUCERA Xenon Light Source CLV-260 NBI. 


\section{REFERENCES}

1. Lin YC, Wang WH, Lee KF, Tsai WC, Weng HH. Value of narrow band imaging endoscopy in early mucosal head and neck cancer. Head Neck 2012;34:1574-1579.

2. Forastiere A, Koch W, Trotti A, Sidransky D. Head and neck cancer. N Engl J Med 2001;345:1890-1900.

3. Muto M, Nakane M, Katada C, et al. Squamous cell carcinoma in situ at oropharyngeal and hypopharyngeal mucosal sites. Cancer 2004;101: 1375-1381.

4. Piazza C, Dessouky O, Peretti G, Cocco D, De Benedetto L, Nicolai P. Narrow-band imaging: a new tool for evaluation of head and neck squamous cell carcinomas. Review of the literature. Acta Otorhinolaryngol Ital 2008;28:49-54

5. Gono K, Yamazaki K, Doguchi N, et al. Endoscopic observation of tissue by narrowband illumination. Opt Rev 2003;10:211-215.

6. Wang WH, Lin YC, Lee KF, Weng HH. Nasopharyngeal carcinoma detected by narrow-band imaging endoscopy. Oral Oncol 2011;47:736741.

7. Katada C, Nakayama M, Tanabe S, et al. Narrow band imaging for detecting superficial oral squamous cell carcinoma: a report of two cases. Laryngoscope 2007;117:1596-1599.

8. Watanabe A, Taniguchi M, Tsujie H, Hosokawa M, Fujita M, Sasaki S. The value of narrow band imaging for early detection of laryngeal can- cer. Eur Arch Otorhinolaryngol 2009;266:1017-1023.

9. Sano Y, Kobayashi M, Hamamoto Y, et al. New diagnostic method based on color imaging using narrowband imaging (NBI) endoscopy system for gastrointestinal tract. Gastrointest Endosc 2001;53:AB125.

10. Lin YC, Watanabe A, Chen WC, Lee KF, Lee IL, Wang WH. Narrowband imaging for early detection of malignant tumors and radiation effect after treatment of head and neck cancer. Arch Otolaryngol Head Neck Surg 2010;136:234-239.

11. Wang WH, Lin YC, Chen WC, Chen MF, Chen CC, Lee KF. Detection of mucosal recurrent nasopharyngeal carcinomas after radiotherapy with narrow-band imaging endoscopy. Int J Radiat Oncol Biol Phys 2012; 83:1213-1219.

12. Jo WK, Eun SS, Shin SH. Feasibility of light-emitting diode uses for annular reactor inner-coated with $\mathrm{TiO} 2$ or nitrogen-doped $\mathrm{TiO} 2$ for control of dimethyl sulfide. Photochem Photobiol 2011;87:1016-1023.

13. Epstein JB, Silverman S Jr, Epstein JD, Lonky SA, Bride MA. Analysis of oral lesion biopsies identified and evaluated by visual examination, chemiluminescence and toluidine blue. Oral Oncol 2008;44:538-544.

14. Sciubba JJ. Oral cancer and its detection. History-taking and the diagnostic phase of management. J Am Dent Assoc 2001;132(Suppl):12S$18 \mathrm{~S}$

15. Lingen MW, Kalmar JR, Karrison T, Speight PM. Critical evaluation of diagnostic aids for the detection of oral cancer. Oral Oncol 2008;44:10-22. 